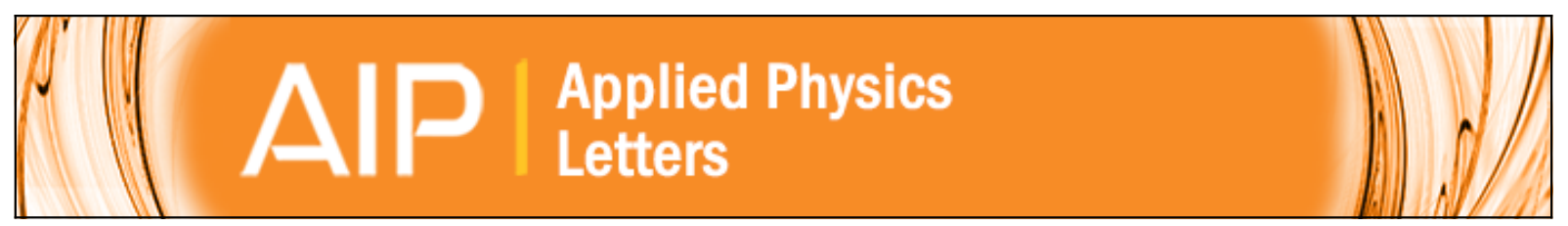

\title{
Surface plasma pretreatment for enhanced diamond nucleation on AIN
}

P. Pobedinskas, G. Degutis, W. Dexters, W. Janssen, S. D. Janssens, B. Conings, B. Ruttens, J. D'Haen, H.-G. Boyen, A. Hardy, M. K. Van Bael, and K. Haenen

Citation: Applied Physics Letters 102, 201609 (2013); doi: 10.1063/1.4807591

View online: http://dx.doi.org/10.1063/1.4807591

View Table of Contents: http://scitation.aip.org/content/aip/journal/apl/102/20?ver=pdfcov

Published by the AIP Publishing 


\title{
Surface plasma pretreatment for enhanced diamond nucleation on AIN
}

\author{
P. Pobedinskas, ${ }^{1,2, a)}$ G. Degutis, ${ }^{1}$ W. Dexters, ${ }^{1}$ W. Janssen, ${ }^{1,2}$ S. D. Janssens, ${ }^{1,2}$ \\ B. Conings, ${ }^{1}$ B. Ruttens, ${ }^{1,2}$ J. D'Haen, ${ }^{1,2}$ H.-G. Boyen, ${ }^{1,2}$ A. Hardy, ${ }^{1,2}$ M. K. Van Bael,,${ }^{1,2}$ \\ and K. Haenen ${ }^{1,2, b)}$ \\ ${ }^{1}$ Institute for Materials Research (IMO), Hasselt University, B-3590 Diepenbeek, Belgium \\ ${ }^{2} I M O M E C, I M E C$ vzw, B-3590 Diepenbeek, Belgium
}

(Received 21 February 2013; accepted 7 May 2013; published online 23 May 2013)

\begin{abstract}
The surface of polycrystalline aluminum nitride (AIN) thin films is exposed to different gas discharge plasmas $\left(\mathrm{N}_{2}, \mathrm{O}_{2}\right.$, and $\left.\mathrm{CF}_{4}\right)$ followed by a water-based colloidal seeding of ultra-dispersed nanodiamond particles. Fluorination of the AlN surface enhances the seeding density, whereas the oxidized surface does not yield any nucleation sites. In the former case, the seeding density improves by almost three orders of magnitude as compared to the untreated and $\mathrm{N}_{2}$ pretreated samples, and allows to grow pinhole-free nanocrystalline diamond film on AlN. Finally, we demonstrate a route towards selective diamond growth on AlN thin films by employing $\mathrm{CF}_{4}$ plasma pretreatment together with photolithography. (C) 2013 AIP Publishing LLC. [http://dx.doi.org/10.1063/1.4807591]
\end{abstract}

Chemical vapor deposition (CVD) diamond is a versatile material with extreme mechanical, thermal, electronic, and optical properties. Because of its very good chemical stability and bio-inertness, it is currently being studied for a range of applications that make use of its surface and bulk properties, including novel generation of neuroprosthetics ${ }^{1,2}$ and (bio-sensing) diamond-based acoustic devices. ${ }^{3}$ As diamond is not a piezoelectric material, its heterostructure with a good piezoelectric material, e.g., aluminum nitride (AIN), is a prerequisite to fulfill the promising role that diamond is envisaged to play within acoustic devices. ${ }^{4}$ However, AlN degrades in water. ${ }^{5}$ Therefore, a pinhole-free layer, e.g., CVD diamond, on AlN is essential for devices that are operated in a water-based environment, at the same time opening up extra functionalities that come with the use of the versatile diamond surface. ${ }^{6,7}$

The synthesis of nanocrystalline diamond (NCD) thin films $(\leq 100 \mathrm{~nm})$ by the microwave plasma enhanced CVD (MW PE CVD) technique has proved an enormous step forward for this material. ${ }^{89} \mathrm{NCD}$ growth on foreign substrates requires artificial formation of diamond nucleation sites on the substrate's surface. The state-of-the-art seeding procedure by water-based colloid of ultra-dispersed nanodiamond (ND) powder allows the deposition of closed films of less than $100 \mathrm{~nm}$ on 2D as well as 3D structures, minimizing growth times while retaining an acceptable surface roughness. ${ }^{10}$

In the colloidal seeding procedure, the surface of a substrate and ND particles' zeta-potential are the most important factors that determine the nucleation density. Hees et al. showed that it is possible to vary the NDs zeta-potential by hydrogenation and in this way to control the seeding density on AlN. ${ }^{11}$ In this Letter, we demonstrate that a plasmainduced modification of the AlN surface drastically influences the seeding density of ND particles. An explanation for this observation is given. Finally, we achieve selective seeding and NCD growth on AlN thin films using the surface plasma pretreatment in combination with photolithography.

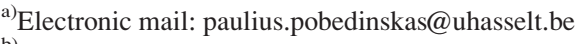

b)Electronic mail: ken.haenen@uhasselt.be
}

Four sample series were prepared starting with a $540 \mathrm{~nm}$ thick AIN layer deposited by DC-pulsed reactive sputtering on silicon substrates. ${ }^{12}$ After the deposition, samples were exposed in situ to different plasmas: nitrogen $\left(\mathrm{N}_{2}\right)$, oxygen $\left(\mathrm{O}_{2}\right)$, and tetrafluoromethane $\left(\mathrm{CF}_{4}\right)$. One sample series was left untreated as a reference. To achieve the gas discharge plasma, the samples were biased negatively under the conditions given in Table I. After the pretreatment, wetting properties, morphology, and chemical composition of the surface were investigated and NDs were seeded on separate samples prepared simultaneously under identical conditions. Surface wetting properties were evaluated by the sessile drop technique using deionized (DI) water. ${ }^{7}$ Surface morphology was assessed with a Veeco NanoScope III MultiMode atomic force microscope (AFM). The surface chemical composition was determined by X-ray photoelectron spectroscopy (XPS) using a Physical Electronics (PHI) 5600LS electron spectrometer equipped with a small spot $\mathrm{X}$-ray source providing monochromatized $\mathrm{AlK}_{\alpha}$ photons $(1486.6 \mathrm{eV})$. The seeding was performed by sample immersion into an aqueous ND colloid for few seconds followed by DI water rinsing and drying using a spin-coater. The colloid was prepared from the detonation ND powder provided by the NanoCarbon Institute Co., Ltd. The size of the NDs is 6 to $7 \mathrm{~nm}$ and the zeta-potential is $(49 \pm 5) \mathrm{mV}$ as measured by dynamic light scattering. The $\mathrm{pH} 4.8$ was determined for the colloid by standard calibrated $\mathrm{pH}$ meter. The contact angle measurement, the transfer into the XPS system, and ND seeding were done within $5 \mathrm{~min}$ after the AlN film deposition.

A calculation of a seeding density $N$ was attempted by analyzing the AFM images (Fig. 1). However, in case of

TABLE I. Plasma pretreatment parameters.

\begin{tabular}{lccccc}
\hline \hline Gas & $\begin{array}{c}\text { Flow } \\
(\mathrm{sccm})\end{array}$ & $\begin{array}{c}\text { Pressure } \\
(\text { mTorr })\end{array}$ & $\begin{array}{c}\text { Voltage } \\
(\mathrm{V})\end{array}$ & $\begin{array}{c}\text { Current } \\
(\mathrm{A})\end{array}$ & $\begin{array}{c}\text { Exposure } \\
\text { time (min) }\end{array}$ \\
\hline $\mathrm{N}_{2}$ & 50 & 10 & 430 & 0.69 & 3 \\
$\mathrm{O}_{2}$ & 30 & 5 & 424 & 0.70 & 3 \\
$\mathrm{CF}_{4}$ & 42 & 17 & 400 & 0.74 & 2 \\
\hline \hline
\end{tabular}


AFM: Before ND seeding

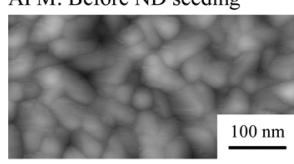

AFM: After ND seeding

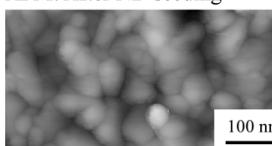

$100 \mathrm{~nm}$

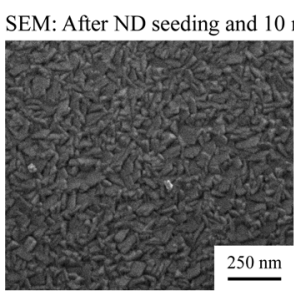

(a) Ref., $\theta<4^{\circ}, R_{\mathrm{q}}=3.4 \mathrm{~nm}$, $N=2 \times 10^{8} \mathrm{~cm}^{-2}$.
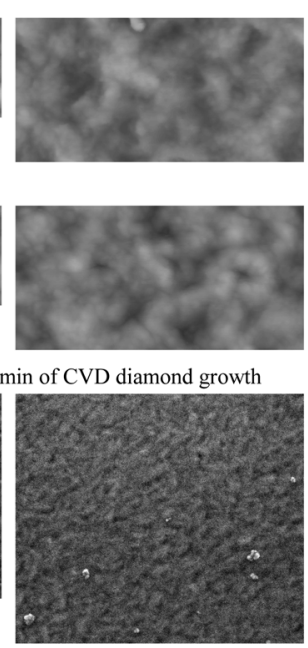

(b) $\mathrm{N}_{2}, \theta<4^{\circ}, R_{\mathrm{q}}=3.0 \mathrm{~nm}$, $N=5 \times 10^{8} \mathrm{~cm}^{-2}$
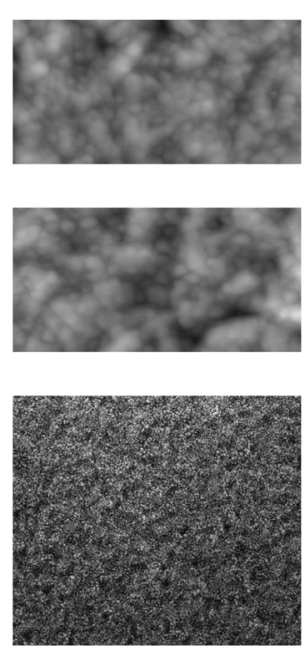

(c) $\mathrm{O}_{2}, \theta<4^{\circ}, R_{\mathrm{q}}=2.8 \mathrm{~nm}$, $N=0 \mathrm{~cm}^{-2}$.
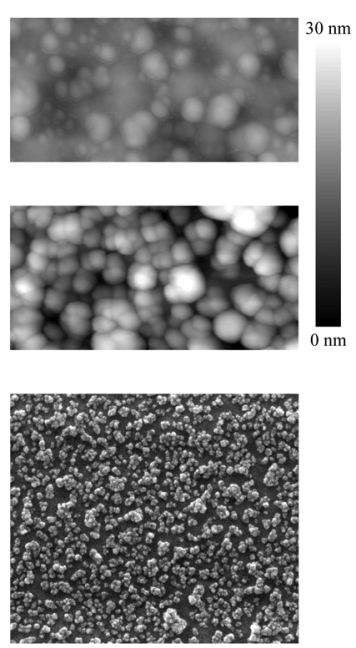

(d) $\mathrm{CF}_{4}, \theta<4^{\circ}, R_{\mathrm{q}}=3.8 \mathrm{~nm}$, $N=1 \times 10^{11} \mathrm{~cm}^{-2}$.
FIG. 1. Surface as seen by AFM (height images) and SEM of (a) untreated AlN sample and pretreated with plasmas: $\mathrm{N}_{2}$ (b), $\mathrm{O}_{2}$ (c), and $\mathrm{CF}_{4}$ (d). Some ND seeds are visible in SEM (a) and (b) images, none in (c) and abundance of NDs in (d). The contact angle $\theta$ and surface roughness $R_{\mathrm{q}}$ were measured after the plasma pretreatment. The seeding density $N$ was calculated from SEM images. very low $N$, it is difficult to spot ND seeds or distinguish them from surface irregularities. Only in case of $\mathrm{CF}_{4}$ plasma pretreated sample, where abundance of agglomerated ND seeds is observed, $N \approx 1.1 \times 10^{11} \mathrm{~cm}^{-2}$ is estimated. In order to confirm the AFM observation, the seeded samples were exposed to $\mathrm{CH}_{4}: \mathrm{H}_{2}(1: 50)$ plasma in an ASTeX 6500 series MW PE CVD reactor. ${ }^{7}$ The substrate temperature was kept at $700{ }^{\circ} \mathrm{C}$ using $3500 \mathrm{~W}$ of MW power and a total gas pressure of 30 Torr. The diamond growth was initiated for 10 min to enlarge the ND seeds, so that they could be visualized by means of a FEI Quanta 200 scanning electron microscope (SEM) equipped with field emission gun thus allowing to determine $N$ as well (Fig. 1). The advantage of SEM images against AFM is the contrast between the materials. The ND seeding on untreated and $\mathrm{N}_{2}$ pretreated AlN surfaces is not very efficient as the nucleation densities achieved are $2 \times 10^{8} \mathrm{~cm}^{-2}$ and $5 \times 10^{8} \mathrm{~cm}^{-2}$, respectively (Figs. 1(a) and 1(b)). The surface pretreatment by $\mathrm{O}_{2}$ plasma does not yield any nucleation sites (Fig. 1(c)), whereas, after $\mathrm{CF}_{4}$ plasma

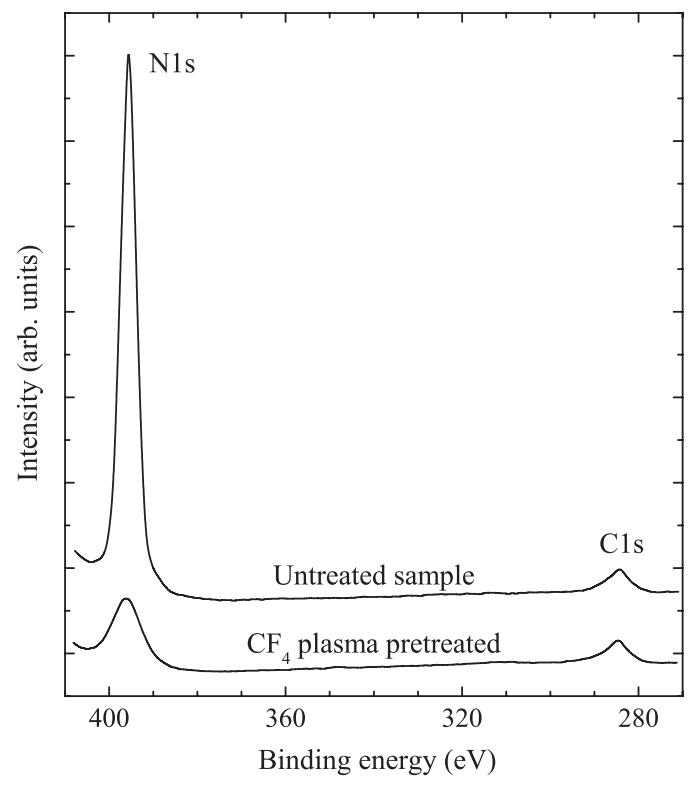

FIG. 2. XPS spectra of untreated and $\mathrm{CF}_{4}$ plasma pretreated AlN. The curves are shifted for clarity. exposure, the surface coverage by ND particles reaches $1 \times$ $10^{11} \mathrm{~cm}^{-2}$ (Fig. 1(d)), which closely matches the estimate form the AFM image. This observation on the achieved seeding densities after the different pretreatments can neither be linked to the wetting properties nor to the roughness of the surface $R_{\mathrm{q}}$. All the samples showed hydrophilic properties (contact angles $\theta<4^{\circ}$ ) and small $R_{\mathrm{q}}$ variation among the samples ( 2.8 to $3.8 \mathrm{~nm}$ ). Rabinovich et al. developed a model that quantitatively predicts the adhesion force $F$ between a particle and the rough surface ${ }^{13}$

$$
F=\frac{A_{\mathrm{H}} r}{6 h_{0}}\left[\frac{1}{1+r /\left(1.48 R_{\mathrm{q}}\right)}+\frac{1}{\left(1+1.48 R_{\mathrm{q}} / h_{0}\right)^{2}}\right],
$$

where $A_{\mathrm{H}}$ is the Hamaker constant, $r$ is the radius of adhering particle, and $h_{0}$ is the distance of closest approach between a surface and adhering particle $(\approx 0.3 \mathrm{~nm})$. The adhesion force between a ND particle and AIN surface would differ $12 \%$ for the observed variation in surface roughness. Another aspect

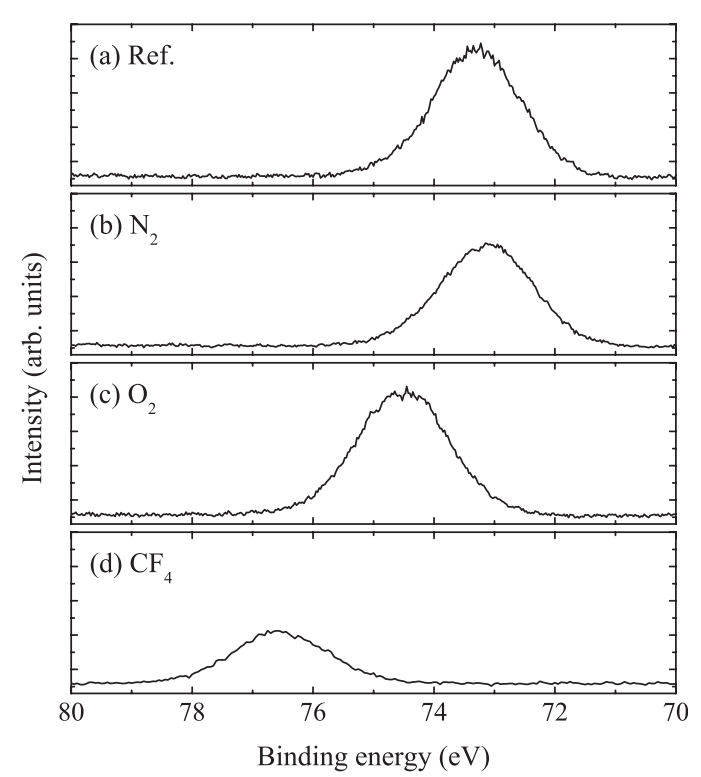

FIG. 3. XPS spectra of $A 12 \mathrm{p}_{3 / 2}$ of untreated AlN (a) and pretreated with plasmas: $\mathrm{N}_{2}(\mathrm{~b}), \mathrm{O}_{2}(\mathrm{c})$, and $\mathrm{CF}_{4}(\mathrm{~d})$. 

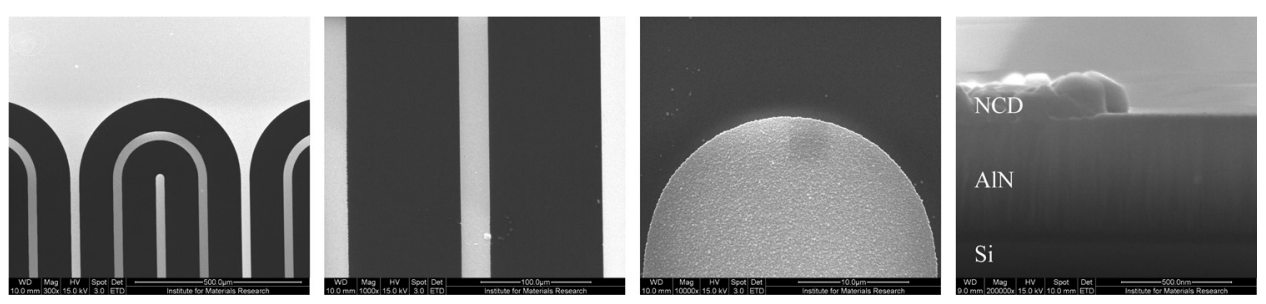

FIG. 4. Selectively grown $150 \mathrm{~nm}$ thick NCD (bright field) on selectively $\mathrm{CF}_{4}$ plasma pretreated AlN surface. Clear lines and rounded shapes of NCD are visible on the pretreated areas.

is that a surface contamination by polymeric fluorocarbon after $\mathrm{CF}_{4}$ plasma pretreatment could be expected. In this case, the surface would become hydrophobic ${ }^{14}$ yielding a low seeding density and consequently a porous NCD film. ${ }^{15}$ However, neither the contact angle measurements nor the XPS survey supports such kind of contamination on the surface. In the latter experiments, one does not observe an increase in the $\mathrm{C} 1 \mathrm{~s}$ photoelectron peak intensity after $\mathrm{CF}_{4}$ plasma pretreatment (Fig. 2). Thus, in all cases, the carbon on the surface is related to the hydrocarbon adsorbed from the ambient air during the transfer from the deposition reactor to the XPS system.

According to the XPS study, exposure of AlN to $\mathrm{N}_{2}$ plasma did not alter the chemical composition of the surface (Figs. 3(a) and 3(b)). This can be inferred from an $\mathrm{Al} 2 \mathrm{p}_{3 / 2}$ core level binding energy of $73.1 \mathrm{eV}$, which matches the value reported for wurtzite AlN. ${ }^{16,17}$ Thus, for $\mathrm{N}_{2}$ plasma pretreated AlN, the density of $\mathrm{ND}$ can be expected to be similar as for the untreated sample, which indeed is confirmed by inspection of SEM images (Figs. 1(a) and 1(b)). After exposure to $\mathrm{O}_{2}$ plasma, the $A 12 \mathrm{p}_{3 / 2}$ photoelectron peak shifts towards a higher binding energy, $74.5 \mathrm{eV}$ (Fig. 3(c)). This indicates the presence of Al-O bonds resulting probably in the formation of $\mathrm{Al}_{2} \mathrm{O}_{3}$. Finally, after $\mathrm{CF}_{4}$ plasma pretreatment, the surface of AlN converts into $\mathrm{AlF}_{3}$ as derived from the $\mathrm{Al}_{2} \mathrm{p}_{3 / 2}$ peak position of $76.6 \mathrm{eV}$ (Fig. 3(d)), which agrees well with previous reports $^{18}$ and reflects the highest oxidation state observed for our plasma pretreated samples. The attenuation of the N1s photoelectrons (Fig. 2) induced by an $\mathrm{AlF}_{3}$ surface layer is quantified resulting in a layer thickness of $3.5 \mathrm{~nm}$ thereby assuming an electron mean free path value of $2.2 \mathrm{~nm} .{ }^{19}$ A similar analysis for the $\mathrm{O}_{2}$ plasma pretreated sample yields a thickness of $4.2 \mathrm{~nm}$ for the $\mathrm{Al}_{2} \mathrm{O}_{3}$ surface layer. Both values agree well with an estimate of the maximum ion penetration depth simulated using SRIM-2013 code $^{20}$ and ion energies as given in Table I.

To explain the link between the seeding density and the functional groups on the surface, the zeta-potential of the ND colloid appears to be crucial. The used ND colloid is water-based, possesses positive zeta-potential and has slightly acidic $\mathrm{pH}$. This situation implies that acidic groups (e.g., R-COOH, R-OH, etc.) are present on the surface of ND particles. ${ }^{21}$ When AlN, i.e., untreated and $\mathrm{N}_{2}$ pretreated samples, is submerged into the water-based colloidal solution, the surface rapidly hydrolyzes by forming $\mathrm{AlOOH}$ and/ or $\mathrm{Al}(\mathrm{OH})_{3}$ in an exothermic reaction. ${ }^{5,22}$ The hydroxyl groups form a positively charged surface at $\mathrm{pH} 4.8$ and the repulsion of ND seeds comes into play. ${ }^{11}$ This explains the low seeding density on these samples. In case of films terminated by $\mathrm{Al}_{2} \mathrm{O}_{3}$, i.e., after $\mathrm{AlN}$ exposure to an $\mathrm{O}_{2}$ plasma, the following compounds form at the surface in aqueous environment: $\mathrm{Al}_{3} \mathrm{OH}, \mathrm{Al}_{2} \mathrm{OH}$, and $\mathrm{AlOH}_{2} \cdot{ }^{23}$ This leads to the assumption that the surface has also a positive charge at $\mathrm{pH} 4.8$ thus strongly repelling ND seeds as none of them is detected on the surface after the seeding procedure. In the final case, the $\mathrm{AlF}_{3}$ hydrolyzes and adsorbs water during the seeding and possibly $\mathrm{AlF}_{3}$ coexists with $\mathrm{AlF}_{3-x}(\mathrm{OH})_{x}$ on the surface. ${ }^{24}$ Fluorine atoms having the highest electronegativity attract valence electrons from aluminum. The ionic bond $\mathrm{Al}-\mathrm{F}$ is so strong that electrons are practically attached to $\mathrm{F}^{25,26}$ Here, the presumption of the F presence at the surface has to be made. ${ }^{18,24}$ In that case, electrons are attracted from the bulk to the surface at $\mathrm{F}$ sites. The consequent negative charge at $\mathrm{F}$ attracts the ND seeds and a very strong hydrogen bond forms between $\mathrm{F}$ and $\mathrm{R}-\mathrm{COOH} .{ }^{27}$ This ensures a good adhesion of NDs on the surface and explains the high nucleation density of ND particles after $\mathrm{CF}_{4}$ plasma pretreatment, which is almost three orders of magnitude higher than on plasma untreated AlN surface.

Finally, to demonstrate the application of two different surface properties, the plasma pretreatment and photolithography were employed to achieve the selective seeding and subsequent selective diamond growth on AIN. Prior to the plasma pretreatment, the surface of AlN was covered by a NR7-3000P photoresist (Futurrex, Inc.). The photoresist was patterned to provide an opening for $\mathrm{CF}_{4}$ plasma exposure (1 min). Afterwards, the photoresist was removed in an acetone ultrasonic bath, the sample was seeded, and NCD was grown selectively (Fig. 4). The NCD growth was performed at 35 Torr pressure for $28 \mathrm{~min}$. The thickness of the film was monitored in situ by measuring a reflection of a laser beam $(473 \mathrm{~nm})$ that created interference fringes. The NCD growth was stopped at $150 \mathrm{~nm}$ film thickness.

In conclusion, surface charge and chemical groups are important for ND seeding. The seeding and in turn NCD growth directly on AIN has proven to be very difficult due to its surface properties, hampering seeding, and subsequent growth. The pretreatment of the AlN surface with $\mathrm{CF}_{4}$ plasma significantly enhanced the density of ND particles due to formation of $\mathrm{AlF}_{3}$. This led to a sufficiently high nucleation density, $1 \times 10^{11} \mathrm{~cm}^{-2}$, and allowed to form a pinhole-free NCD layer on top of piezoelectric material. Additionally, a simple route towards selective diamond growth was shown. On AlN surface areas, which were protected by a photoresist during the $\mathrm{CF}_{4}$ plasma pretreatment, the ND seeds were repelled, whereas the exposed areas converted into $\mathrm{AlF}_{3}$ and exhibited high adhesion of the ND seeds. Thus, the distinct surfaces properties of $\mathrm{AlN}$ and $\mathrm{AlF}_{3}$ played the key role in the successive selective seeding and growth of NCD film.

This work was financially supported by the Research Foundation Flanders (FWO) (G.0568.10N and G.0456.12), the 
EU FP7 through Marie Curie ITN "MATCON" (PITN-GA2009-238201) and the Collaborative Project "MOLESOL" (No. 256617), and the Methusalem "NANO network."

${ }^{1}$ M. Dankerl, B. Hofmann, S. Eick, M. Hauf, S. Ingebrandt, A. Offenhäuser, M. Stutzmann, and J. A. Garrido, Adv. Funct. Mater. 19, 2915 (2009).

${ }^{2}$ P. Bergonzo, A. Bongrain, E. Scorsone, A. Bendali, L. Rousseau, G. Lissorgues, P. Mailley, Y. Li, T. Kauffmann, F. Goy, B. Yvert, J. A. Sahel, and S. Picaud, IRBM News 32, 91 (2011).

${ }^{3}$ V. Mortet, O. A. Williams, and K. Haenen, Phys. Status Solidi A 205, 1009 (2008).

${ }^{4}$ J. G. Rodríguez-Madrid, G. F. Iriarte, J. Pedrós, O. A. Williams, D. Brink, and F. Calle, IEEE Electron Device Lett. 33, 495 (2012).

${ }^{5}$ T. Graziani and A. Bellosi, Mater. Chem. Phys. 35, 43 (1993).

${ }^{6}$ B. van Grinsven, N. V. Bon, H. Strauven, L. Grieten, M. Murib, S. D. Janssens, K. Haenen, M. J. Schöning, V. Vermeeren, M. Ameloot, L. Michiels, R. Thoelen, W. D. Ceuninck, and P. Wagner, ACS Nano 6, 2712 (2012).

${ }^{7}$ S. D. Janssens, S. Drijkoningen, M. Saitner, H.-G. Boyen, P. Wagner, K. Larsson, and K. Haenen, J. Chem. Phys. 137, 044702 (2012).

${ }^{8}$ O. A. Williams, V. Mortet, M. Daenen, and K. Haenen, Appl. Phys. Lett. 90, 063514 (2007).

${ }^{9}$ O. A. Williams, M. Nesladek, M. Daenen, S. Michaelson, A. Hoffman, E. Ōsawa, K. Haenen, and R. B. Jackman, Diamond Relat. Mater. 17, 1080 (2008).

${ }^{10}$ O. A. Williams, O. Douhéret, M. Daenen, K. Haenen, E. Ōsawa, and M. Takahashi, Chem. Phys. Lett. 445, 255 (2007).

${ }^{11}$ J. Hees, N. Heidrich, W. Pletschen, R. E. Sah, M. Wolfer, O. A. Williams, V. Lebedev, C. E. Nebel, and O. Ambacher, Nanotechnology 24, 025601 (2013).
${ }^{12}$ P. Pobedinskas, J.-C. Bolsée, W. Dexters, B. Ruttens, V. Mortet, J. D’Haen, J. V. Manca, and K. Haenen, Thin Solid Films 522, 180 (2012).

${ }^{13}$ Y. I. Rabinovich, J. J. Adler, A. Ata, R. K. Singh, and B. M. Moudgil, J. Colloid Interface Sci. 232, 10 (2000).

${ }^{14}$ A. Terriza, R. Álvarez, A. Borrás, J. Cotrino, F. Yubero, and A. R. González-Elipe, J. Colloid Interface Sci. 376, 274 (2012).

${ }^{15}$ M. Tsigkourakos, T. Hantschel, S. D. Janssens, K. Haenen, and W. Vandervorst, Phys. Status Solidi A 209, 1659 (2012).

${ }^{16}$ D. Manova, V. Dimitrova, W. Fukarek, and D. Karpuzov, Surf. Coat. Technol. 106, 205 (1998).

${ }^{17}$ L. Rosenberger, R. Baird, E. McCullen, G. Auner, and G. Shreve, Surf. Interface Anal. 40, 1254 (2008).

${ }^{18}$ A. Makarowicz, C. L. Bailey, N. Weiher, E. Kemnitz, S. L. M. Schroeder, S. Mukhopadhyay, A. Wander, B. G. Searle, and N. M. Harrison, Phys. Chem. Chem. Phys. 27, 5664 (2009).

${ }^{19}$ C. J. Powell and A. Jablonski, NIST Electron Inelastic-Mean-Free-Path Database (National Institute of Standards and Technology, Gaithersburg, MD, 2010).

${ }^{20}$ J. F. Ziegler, M. D. Ziegler, and J. P. Biersack, Nucl. Instrum. Methods Phys. Res. B 268, 1818 (2010).

${ }^{21}$ H. Boehm, Carbon 32, 759 (1994).

${ }^{22}$ C. Chambers and A. K. Holliday, Modern Inorganic Chemistry: An Intermediate Text (Butterworths, London, 1975).

${ }^{23}$ J. Sung, Y. R. Shen, and G. A. Waychunas, J. Phys.: Condens. Matter 24, 124101 (2012).

${ }^{24}$ C. L. Bailey, S. Mukhopadhyay, A. Wander, B. G. Searle, and N. M. Harrison, J. Phys. Chem. C 113, 4976 (2009).

${ }^{25}$ D. König and G. Ebest, Solid-State Electron. 44, 111 (2000).

${ }^{26}$ D. König, G. Ebest, R. Scholz, S. Gemming, I. Thurzo, T. U. Kampen, and D. R. T. Zahn, Physica E 14, 259 (2002).

${ }^{27}$ J. Emsley, Chem. Soc. Rev. 9, 91 (1980). 